\title{
Purine nucleoside phosphorylase inhibitors - an immunotherapy with novel mechanism of action for the treatment of melanoma
}

\author{
Shanta Bantia
}

From 30th Annual Meeting and Associated Programs of the Society for Immunotherapy of Cancer (SITC 2015) National Harbor, MD, USA. 4-8 November 2015

\section{Introduction}

Contrary to expectations based on the immuno-compromised clinical phenotype of the PNP-deficient patients, the present study demonstrates that PNP inhibitors (PNPi) can activate immune cells that can help mount a robust antitumor response. PNP deficiency in humans lead to elevation of plasma guanosine [1]. In the present study, we demonstrate that guanosine can activate toll like receptor 2 (TLR2) and TLR4. Powerful immune-stimulatory properties of TLR2 and TLR4 agonist have been exploited for their potential as anti-cancer agents and as an adjuvant in cancer vaccines.

\section{Method}

TLR stimulation is tested in-vitro by assessing NF- $\kappa \mathrm{B}$ activation in HEK293 cells expressing a given TLR. In mouse melanoma model, cancer cells were injected subcutaneously and treatment with the NTR001 was initiated on day 6 after injection of tumor cells. Tumor volume and survival were recorded every 3-4 days. Mouse tetanus toxoid vaccine model was used to evaluate the adjuvant effect of NTR001.

\section{Results}

Guanosine (100 uM) exhibits a significant stimulatory effect on human TLR2 and TLR4 ( $\mathrm{p}<0.0001$ vs vehicle), alone and in combination with PNPi, NTR001 (10 $\mathrm{uM}$ ). Guanosine demonstrates no effect on TLR3, TLR5, TLR7, TLR8 and TLR9. NTR001 as single agent demonstrates no effect on any of the TLRs. Treatment with NTR001 at doses $30 \mathrm{mg} / \mathrm{kg}$ every other week given p.o. and $5 \mathrm{mg} / \mathrm{kg}$ given every day in drinking water resulted in a significant decrease in tumor volume compared to the vehicle treated group $(30 \mathrm{mg} / \mathrm{kg}$ and $5 \mathrm{mg} / \mathrm{kg} \mathrm{p}<$ 0.05 vs vehicle). Twenty percent of mice survived in the $5 \mathrm{mg} / \mathrm{kg}$ dose group whereas no mice survived in the vehicle and $30 \mathrm{mg} / \mathrm{kg}$ dose groups. The immune potentiating effect of NTR001 was further confirmed in mouse tetanus toxoid model where it demonstrated increase in both antibody titers and interferon-g levels.

\section{Conclusion}

PNP inhibitors represent a novel approach, to enhance the immune system through activation of TLR2 and TLR4, for the treatment of melanoma and other malignancies. Combinations of NTR001 and/or guanosine with other cancer immunotherapies such as checkpoint modulators, CTLA-4 antagonist, PD-1 antagonist, and IDO-1 inhibitors will be explored further.

Published: 4 November 2015

doi:10.1186/2051-1426-3-S2-P292

Cite this article as: Bantia: Purine nucleoside phosphorylase inhibitors an immunotherapy with novel mechanism of action for the treatment of melanoma. Journal for ImmunoTherapy of Cancer 2015 3(Suppl 2):P292.

Nitor Therapeutics, Birmingham, AL, USA 